\title{
The Contribution of Osteoprogenitor Cells to Arterial Stiffness and Hypertension
}

\author{
Maria Pikilidou $^{\mathrm{a}}$ Maria Yavropoulou $^{\mathrm{b}}$ Maria Antoniou ${ }^{\mathrm{a}}$ John Yovos $^{\mathrm{b}}$

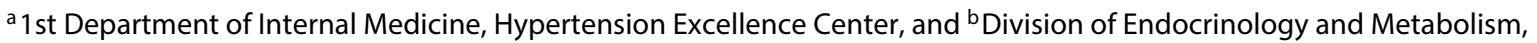 \\ AHEPA University Hospital, Thessaloniki, Greece
}

\section{Key Words}

Osteoprogenitor cells · Arterial stiffness · Hypertension .

Vascular calcification

\begin{abstract}
Hypertension, the major cause of cardiovascular disease, is bidirectionally linked to arterial stiffness. Evidence shows that vascular calcification, either medial or intimal, induces arterial stiffening further worsening hypertension parallel to substantially increasing cardiovascular risk. The disturbance in the bone-vascular axis that leads to the increase of calcium deposition in the arterial wall may be the result of a shift in the functionality of bone marrow-derived circulating stem cells with a calcifying potential, namely osteoprogenitor cells. These cells deposit bone matrix proteins in the vascular wall that can subsequently become mineralized. The current notion is that these cells derive from diverse cell lines. The present review summarizes the current knowledge on the role of progenitor cells with a calcifying potential on arterial calcification, stiffness and hypertension.
\end{abstract}

(C) 2015 S. Karger AG, Basel

\section{Introduction}

Osteoprogenitor cells (OPCs) are known to be the progenitors of osteoblasts. They are known to contribute to new bone tissue formation [1] and fracture repair [2]. Current knowledge, however, suggests that not only these circulating bone marrow-derived stem cells can give rise to cells morphologically and functionally different from osteoblasts, but also that OPCs can derive from different cell types such as monocytes, pericytes and vascular smooth muscle cells (VSMCs) outside the bone microenviroment $[3,4]$. All these types of cells, including the ones derived from bone marrow, have been implicated in the formation of ectopic calcification.

The most clinically important site of ectopic calcification is arterial calcification. It is a phenomenon of disturbed calcium deposition, as part of the calcium that is supposed to be deposited in our bones is lodged in our vessels [5]. This pathology of the bone-vascular axis (osteoporosis and vascular calcification, VC) is typically associated with aging and accelerated by age-related diseases such as kidney disease and diabetes.

OPCs, also called circulating calcifying cells, are thought to play a pivotal role in this bone-vascular axis. These cells deposit bone matrix proteins in the vascular wall that can subsequently become mineralized. The ability of OPCs to calcify in vivo is related to the expression of bone-related genes, especially transcription factor Runx-2, a master gene regulator of osteogenesis [6]. Other transcription factors that induce osteogenic expression are Cbfa1, Msx2 and Sox9; these may also affect OPCs to induce arterial calcification [3].

The ectopic arterial calcium deposition is discriminated into medial and intimal and is predictive of cardiovascular morbidity and mortality [7]. There are two forms of VC, each with a distinct anatomical distribution and clin-

\section{KARGER 125}

2015 S. Karger AG, Base

$1018-1172 / 15 / 0521-0032 \$ 39.50 / 0$ 


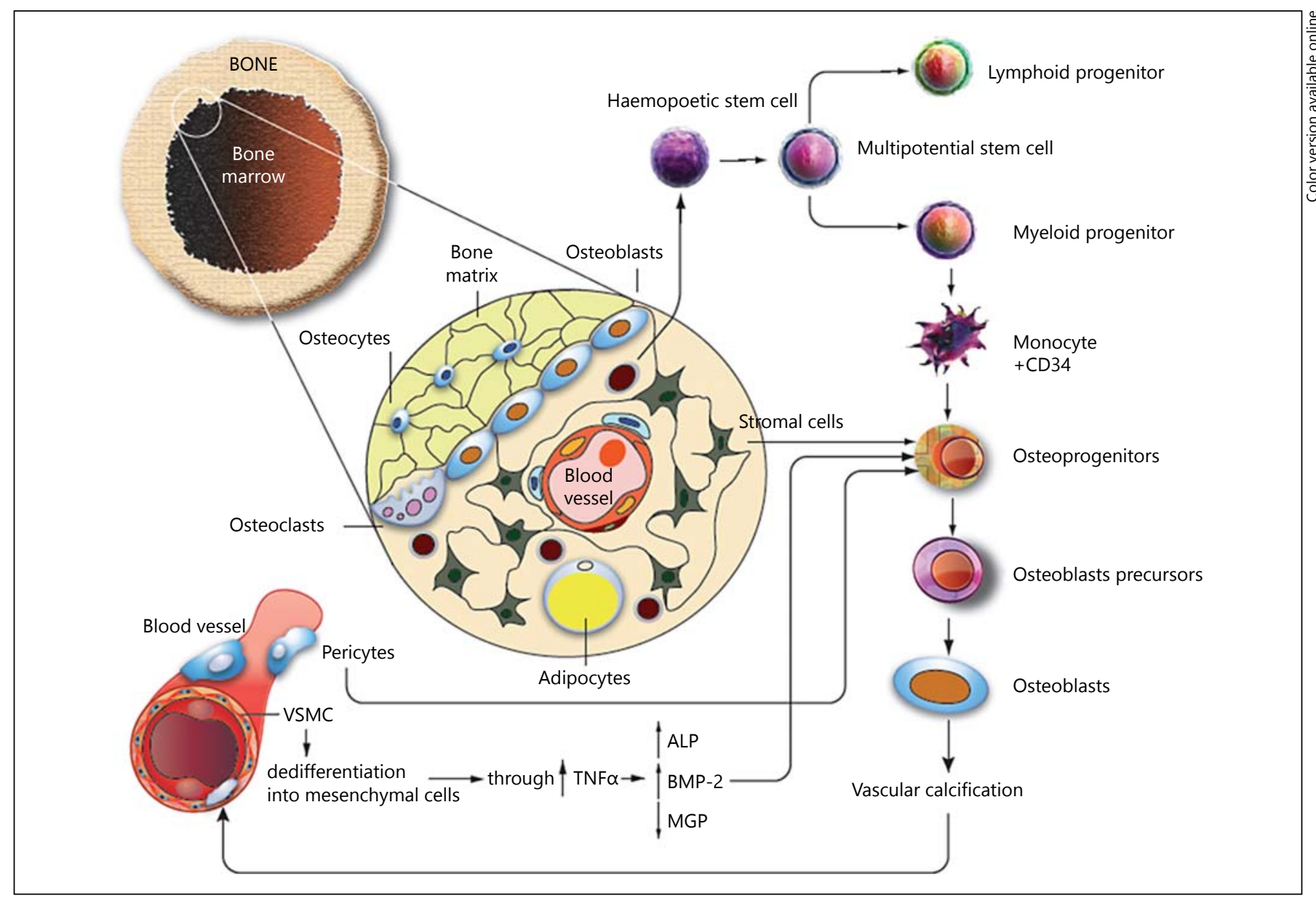

Fig. 1. The origin of OPCs. These cells derive from 1) the hemopoetic cell line that gives rise to monocytes and macrophages, 2) mesenchymal cells, 3) perivascular pericytes, 4) VSMCs and 5) stromal cells.

ical relevance, namely the intimal and medial calcification, the latter being more widely known as medial elastocalcinosis or Mockenberg's disease [8]. Intimal calcification involves the lipid-rich fibrous cap of the atheroma and is likely to be the net result of a balance of factors favoring and inhibiting calcification. The former factors include apoptotic cell death of VSMCs and macrophages, calcification stimulatory proteins, lipids and mechanisms which increase the calcium and phosphate extracellular concentration, while the latter factors include phagocytosis, calcification inhibitory proteins and, potentially, osteoclast macrophages [9].

Medial elastocalcinosis is a less frequent phenomenon and characterizes mainly diabetic and chronic kidney disease $(\mathrm{CKD})$ patients. Unlike intimal calcification, medial calcification occurs in the absence of lipids or inflammatory cells. It is likely the result of a lack of expression or activity of calcification inhibitory proteins, degeneration of elastic fibers, induction of apoptosis and failure of clearance of apoptotic bodies or a de-regulation of the $\mathrm{pH}$ [9].

Mounting evidence supports that arterial calcification largely affects arterial stiffness, a well-known consequence of vascular aging and the most important contributor to the development of hypertension and its detrimental consequences, namely stroke and myocardial infarction [10-12].

This review summarizes the direct effects/associations of progenitor cells with a calcifying potential, now known as osteoprogenitors, to arterial stiffening and hypertension.

\section{Origin of OPCs}

The current notion on the origin of OPCs is that they derive from diverse cell lines (fig. 1). The concept that there are circulating cells of the osteoblast lineage which 
correlate with markers of bone formation came from Eghbali-Fatourechi et al. [13] in 2005. These cells were thought to be comprised of 2 populations: 1 related to hematopoietic stem cells/endothelial progenitor cells and the other to mesenchymal stem cells [3].

Recently, Fadini et al. [14] showed that there are circulating cells with osteogenic potential that express osteocalcin $(\mathrm{OCN}+)$, bone alkaline phosphatase $(\mathrm{BAP}+)$ and also the Philadelphia chromosome-related BCR-ABL gene complex in patients with chronic myeloid leukemia, demonstrating a myeloid origin. These originate from the bone marrow, although in the same study they also showed that circulating monocytes/macrophages can transform to myeloid calcifying cells by in vitro culture.

Hegyi et al. [15] postulated that OPCs originate from perivascular pericytes, medial VSMCs, adventitial fibroblasts or from the bone marrow stroma, highlighting the strong association between angiogenesis and heterotopic ossification of the skeletal muscle. Pericytes that are present in the new blood vessels may become OPGs, suggesting that these cells may provide the cellular link between ectopic calcification and angiogenesis [16].

Another potential origin of OPCs is the dedifferentiation of artery wall cells into mesenchymal cells such as osteoblasts, the presence of cells with osteoblastic dedifferentiation within the vessel wall $[17,18]$. These cells are likely to be VSMCs. In particular, VSMCs acquire an osteogenic phenotype that is activated by the activation of the elastin and transforming growth factor-b receptors by the respective molecules that are produced by matrix degradation through the elastolytic matrix metalloproteinases [19]. In a recent study, mesenchymal cells enhanced their osteoblastic differentiation by the combined action of bone morphogenetic proteins (BMP) and vascular endothelial growth factor [20].

It also seems that inflammatory cytokines such as TNFa induce elongated VSMCs to transform into a cuboidal cell, which is highly reminiscent of an osteoblast. TNF-a increases calcium deposition and the expression of osteogenic signals like alkaline phosphatase and BMP-2 [21].

OPGs may increase in number in states of high BMP activity, such as when there is a lack of the BMP inhibitor matrix Gla protein (MGP) and hyperglycemia. In this case, an animal study showed that the osteogenic cells are derived from the vascular endothelium. The expression of BMP-2 may be regulated by an $\mathrm{H}_{2} \mathrm{O}_{2}$-mediated activation of NF- $\kappa \mathrm{B}$ both by inflammatory stimuli and by high intravascular pressure [22]. VC could, therefore, be considered an acquired stem cell disorder in these settings $[23,24]$.
A different origin of the OPCs has been proposed depending on whether the calcification is medial or intimal. Speer et al. [25] investigated the origin of cells involved in medial calcification and showed that they derive from smooth muscle cells and not from bone marrow cells. Additionally, Doerhing et al. [26] showed that there are a number of cells in the intimal lesions that are CD34+ and bone marrow-derived.

The induction signals for this acquired osteogenic potential in either bone marrow-derived cells or VSMCs likely comes from the same regulators, namely the BMP/ Smad6 signaling pathways. In this way, the expression of the BMP pathway is highly dependent on the expression of the transcription regulator Runx. On the other hand, loss of inhibitors of VC such as fetuin A or MGP-1 induces matrix vesicle formation and VSMC-induced calcification [26].

A common substrate of osteoporosis and arterial stiffening could be inflammation, which drives bone resorption and promotes vascular disease [27]. Novel research by Al-Aly [21] showed that inflammation has a central role in the generation of vascular cells that calcify in vivo. In this context, the chief inflammatory mediator TNF- $\alpha$ dose-dependently increased Msx $2 \mathrm{mRNA}$ and BMP2 in aortic mural progenitor cells in high-fat fed mice with diabetes.

\section{Arterial Stiffness and Bone Mineral Density}

In the Baltimore Longitudinal Study on Aging (BLSA) [28], there was a significant reverse association between pulse wave velocity (PWV), a reliable surrogate marker of cardiovascular risk, and cross-sectional cortical bone area in women, but not in men, after adjusting for confounders. This finding suggests that mediators of this association probably are differentially regulated between men and women. In this study, in women, every SD decrease in cross-sectional cortical bone area was associated with a 0.14 SD increase in PWV, an effect quite modest, given that age is the major determinant of PWV [28].

Four other studies investigating the association between bone demineralization and arterial stiffness in women also found an inverse relationship between these two variables [29-32]. These studies were all done in osteoporotic women and used dual energy X-ray absorptiometry scans, and all of them showed a greater increase in PWV with every decrease in lumbar spine bone mineral density than the BLSA study. The higher effect size of these studies is probably due to the patient selection, given that the former studies included osteoporotic patients. 
In 2003, Hirose et al. [33] showed that carotid-femoral PWV significantly correlated with the osteo-sono assessment index - an index of bone strength assessed by quantitative ultrasound - in both genders, with a more prominent relationship in females, especially those in menopause. It seems that a common denominator for these observations is the rapid estrogen decrease in early postmenopause and that this can be partially reversed after estrogen replacement. Zaydun et al. [34] provided relevant data suggesting that the age-related increase in arterial stiffness in early postmenopausal phase is at least in part related to estrogen deficiency. Tanaka et al. [35] showed by computed tomography that in patients with rheumatoid arthritis the bone loss was significantly associated with arterial stiffness.

These studies may indicate a possible role in cells that regulate both periarticular bone loss and arterial stiffness and are involved in the bone-vascular axis, such as osteoblasts and their progenitors.

\section{Arterial Calcification, Arterial Stiffness and Hypertension}

We know by now that VC is associated with hypertension and that the onset of arterial calcification occurs at an earlier stage in hypertensive subjects [36]. In these patients, coronary artery calcification seems to predict longterm mortality as shown by a substudy of the INSIGHT trial [7]. Moreover, it has been demonstrated that coronary artery calcification is associated with an increased occurrence of ischemic stroke in hypertensives [7, 37].

The mechanism behind this observation is that arterial calcification causes a progressive reduction in vascular resilience and compliance with a parallel increase in arterial stiffness, which is a major determinant of the rise in systolic blood pressure (BP), the fall in diastolic BP and the acceleration of PWV.

This phenomenon is very prominent in the well-known animal model of VC MGP (-/-) mice. These are knockout mice for MGP, a potent matrix mineralization inhibitor. They are known to be tachycardic with a very high PWV in the aorta at rest, presumably from the dramatic increase in aortic calcium and endothelial dysfunction as evidenced by the minimal inflammatory response to hyperlipidemia and the formation of arteriovenous malformations [38]. These hemodynamic alterations increase the left ventricular load and susceptibility to myocardial ischemia [3].

Several studies proved an association between carotidfemoral PWV and arterial calcification in both animal

Osteoprogenitor Cells, Arterial Stiffness

and Hypertension models and humans (tables 1,2). In CKD, where medial calcification is prominent, indirect evidence in humans showed the calcification inhibitor fetuin-A and the antiosteoclastic factor osteoprotegerin to be independently associated with arterial stiffness [39].

Moreover, in an early study [40] in patients with endstage renal disease, increased VC was associated with increased stiffness of large-capacity elastic-type arteries like the aorta and the common carotid artery. Later, two other human studies verified this association $[41,42]$ (table 2).

Outside of CKD, direct evidence of the VC and arterial stiffness comes from two studies in mice. In the first, medial elastocalcinosis induced by hypervitaminosis $\mathrm{D}$ plus nicotine, demonstrated a strong relationship between the extent of aortic calcification and stiffness measured by several approaches [43]. Essalihi et al. [44] confirmed this data in a warfarin-induced medial elastocalcinosis rat model. The authors concluded that at least one third of the stiffness was related to elastocalcinosis.

In asymptomatic humans, Seo et al. [31] showed that aortic calcification was significantly correlated with carotid-femoral PWV in a study of 193 drug-naïve subjects after adjusting for confounders. In accordance with this, McEniery et al. found a significant association between aortic stiffness and isolated systolic BP [45]. Moreover, in the twin UK study, a significant correlation was found between VC and PWV in a subgroup of 40 women [46]. The largest study ever to assess this relationship was the Multi-Ethnic Study of Atherosclerosis (MESA), in which aortic calcification significantly correlated with carotid arterial stiffness [47].

The role of OPCs in this relationship has been described in an in vitro study where in rats with CKD and VC, smooth muscle cell differentiation to osteoblast-like cell was associated with medial remodeling, which included disruption of the elastic lamellas and deposition of collagen, which was at least in part responsible for the observed arterial stiffness [48].

It is noteworthy that the translation of the rise in PWV velocity to rise in $\mathrm{BP}$ is not parallel, and while the two are interdependent, the rates of their acceleration differ across age and gender. This has been recently demonstrated in two major studies that dissociate PWV from BP trajectories. Specifically, in the BLSA, the rates of PWV increase accelerated with advancing age in men more than in women, leading to gender differences in PWV after the age of 50 [49].

Likewise, in the SardiNIA study, at ages $>40$ years in men, the rates of change in systolic $\mathrm{BP}$ and pulse pressure 
Table 1. Animal studies of the effects of induced VC on arterial stiffness

\begin{tabular}{|c|c|c|c|c|}
\hline $\begin{array}{l}\text { Authors [Ref.], } \\
\text { year }\end{array}$ & $\begin{array}{l}\text { Subject } \\
\text { characteristics }\end{array}$ & Number & Methodology, measurements & Results \\
\hline $\begin{array}{l}\text { Luo et al. [38], } \\
1997\end{array}$ & $\begin{array}{l}\text { Mice lacking the } \\
\text { matrix Gla protein }\end{array}$ & 11 mice & PWV & $\begin{array}{l}\text { Increased PWV and tachycardia. } \\
\text { Mice develop to term but die within } \\
2 \text { months as a result of arterial } \\
\text { calcification which leads to blood vessel } \\
\text { rupture }\end{array}$ \\
\hline
\end{tabular}

$\mathrm{ISH}=$ isolated systolic hypertension; $\mathrm{PP}=$ pulse pressure; $\mathrm{VDN}=$ vitamin $\mathrm{D}_{3}$ and nicotine; $\mathrm{WVK}=$ warfarin and vitamin $\mathrm{K}$.

increase plateaued and then declined, so that the systolic BP itself also declined at older ages, whereas the pulse pressure plateaued [50]. This dissociation may be due to different ways that calcification occurs across age and gender, thus affecting the BP phenotype.

\section{Osteoprogenitors Arterial Stiffness and Cardiovascular Disease}

In 2010, Pirro et al. [51] found for the first time that osteoporotic women had a significantly higher absolute number of OPCs (defined as CD34+/AP+ or CD34+/ $\mathrm{OCN}+$ ) than nonosteoporotic controls, while in the regression analysis, $\mathrm{CD} 34+/ \mathrm{OCN}+$ were significant predictors of aortic PWV, along with systolic BP, heart rate and age after adjusting for CV risk factors, parathyroid hormone levels and osteoporotic status. In this study, osteoporotic women also had a higher PWV compared to controls. The same research group showed that osteoporotic women with abdominal aortic calcium deposition had a higher number of circulating CD15-/AP+/OCN- cells [52].

Mangiafico et al. [53] showed that osteoporotic women had higher PWV, augmentation index and central aor- tic and pulse pressures compared to controls. Pal et al. [54] showed that in patients with peripheral artery disease, circulating osteocalcin-positive mononuclear cells (OCN+ MNCs) were associated with the severity of aortic calcification. In 2010, Pirro et al. [51] demonstrated the $\mathrm{CD} 34+/ \mathrm{OCN}+$ cell population as the cell lineage whose excess is closely related to bone mineral density and arterial stiffening. Gossl et al. [55] found a greater percentage of CD34+/KDR + cells in subjects with early coronary atherosclerosis, characterized by coronary endothelial dysfunction, or in subjects with severe multivessel coronary artery disease compared to those with no structural coronary artery disease.

\section{Future Perspectives}

Despite their origin, OPCs are involved in the extraosseous calcification in vessels, which is a result of the dysregulation of promoters and inhibitors of $\mathrm{VC}$ and may be the result of increased oxidative stress [56]. This ectopic calcification, whether it is intimal or medial, results in arterial stiffness, with its detrimental effects on arterial age. 
Table 2. Human observational studies correlating arterial stiffness with VC

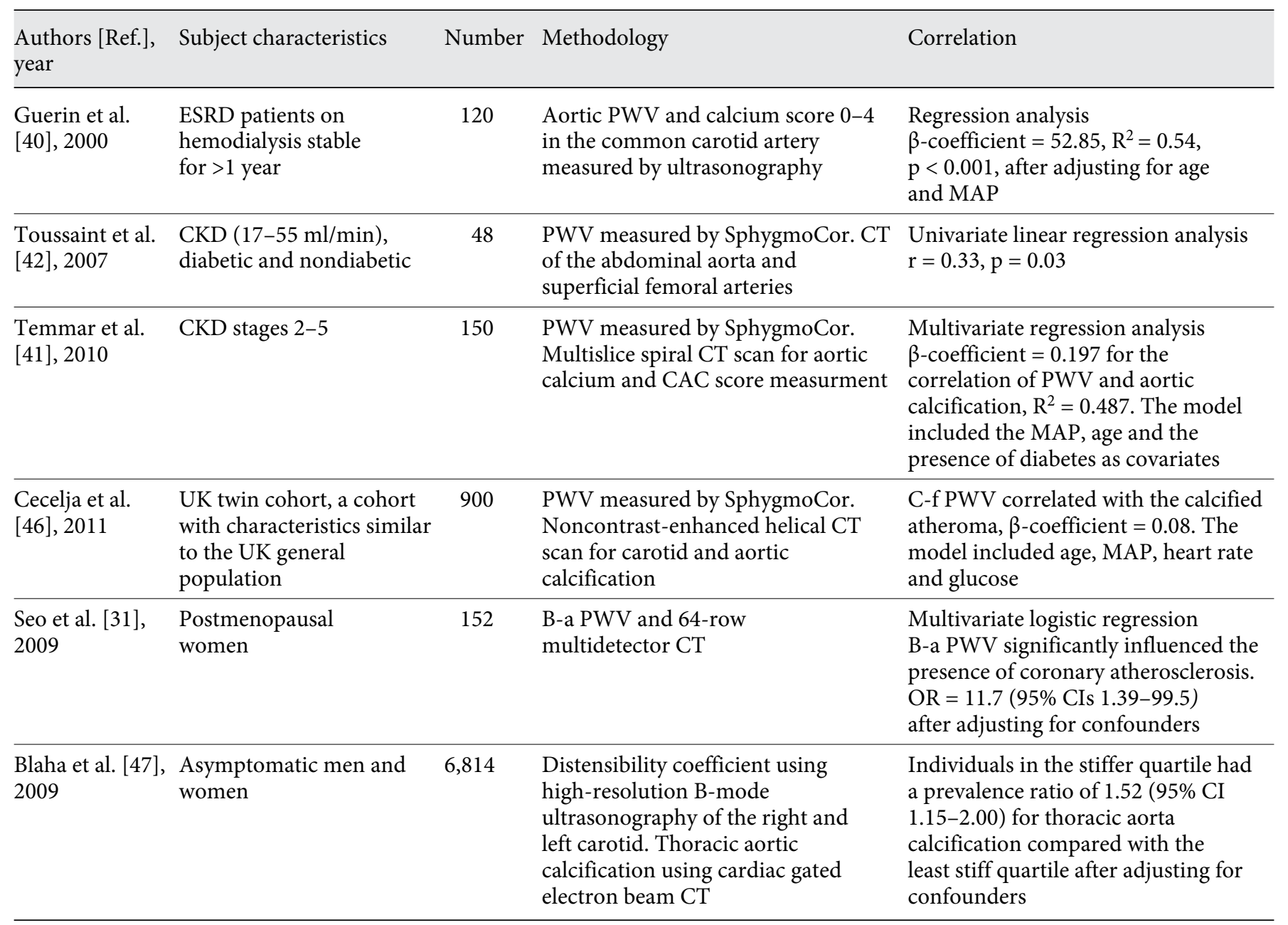

$\mathrm{B}-\mathrm{a}=$ Brachial-ankle; $\mathrm{CT}=$ computed tomography; ESRD = end-stage renal disease $\mathrm{C}$ - $\mathrm{f}=$ carotid-femoral; $\mathrm{MAP}=$ mean arterial pressure; $\mathrm{CAC}=$ coronary arterial calcification.

The role of OPCs in osteoporosis was directly shown by Pirro et al. [57] who found a significantly higher number of $\mathrm{AP}+/ \mathrm{CD} 34+$ and $\mathrm{OCN}+$ in osteoporotic postmenopausal women compared to controls, and the number of $\mathrm{CD} 34+/ \mathrm{OCN}$ was associated with reduced bone mineral density.

Based on this observation, Peris et al. [58] investigated the effect of osteoporosis treatment on the progenitor cellular level. This study showed that treatment with risendronate resulted in the downregulation of osteogenic genes in endothelial progenitor cells and a trend of a reduction of endothelial progenitor cells with osteogenic potential (those coexpressing osteoblastic surface markers and genes). These data may indicate a possible mechanism by which biphosphonates may inhibit VC.

Osteoprogenitor Cells, Arterial Stiffness and Hypertension
Other possible treatments that may have an effect on the OPC number are monoclonal antibodies such as denosumab, an anti-RANKL ligand that significantly attenuated aortic calcium deposition in human RANKL knockin mice with glucocorticoid-induced osteoporosis [59]. However, in humans, denosumab did not influence the 3 -year progression of aortic calcification or the incidence of adverse cardiovascular events in postmenopausal women with osteoporosis and high cardiovascular risk [60].

Another possible monoclonal treatment to intervene in the bone-vascular axis is the new drug romosozumab which targets sclerostin. Sclerostin levels are found to be positively associated with both aortic calcification and arterial stiffness in postmenopausal women [61]. They are also found to be strongly associated with calcifying aortic 
heart valve disease in hemodialysis patients [62]. However, increased sclerostin levels have been associated with improved survival in hemodialysis patients [63].

These aforementioned treatments may provide a unifying approach to the now well-recognized dysregulated bone-vascular axis and disrupted OPC number in agerelated diseases. To what extent these drugs may provide collateral benefits beyond improving osteoporosis, such as improving $\mathrm{VC}$ and stiffness, is yet to be investigated.

Other drugs that may interfere with the bone-vascular axis include tumor-suppressing agents which are inhibitors of the canonical signaling Wnt pathway, which is actively involved in bone formation and $\mathrm{VC}$, such as secreted frizzled-related proteins 2 and 4 and the Dikkopfrelated protein 1. However, especially for secreted frizzled-related proteins, which are circulating secreted proteins, they act systematically and may reduce bone mass [64].

Several antihypertensive drug classes have also been shown to reduce VC [65]. These agents, which include drugs that interfere with the renin-angiotensin axis as well as calcium channel blockers may decrease calcification of VSMCs, thus inhibiting the adoption of an osteogenic phenotype. However, this remains to be investigated.

It is not yet clear whether lowering vascular calcium deposits is beneficial in the long term. The exact implications of VC on plaque stability are still under debate; however, since the distribution of calcification rather than its mere presence may predispose to rupture, plaques with diffused and speckled microcalcium deposits ('spotty calcification') are more vulnerable [66]. In this context, whether therapies targeting OPCs produce favorable outcomes can only be speculated.

Investigating potential targets for treatment at the progenitor cellular level is a novel approach to long-standing debilitating problems such as osteoporosis and cardiovascular disease. Whether killing two birds with one stone is feasible using known treatments remains a challenge for future research.

\section{Conclusions}

There is mounting evidence of a role for OPCs in VC. These cells derive from diverse cell lines. Loss of inhibitors and induction of promoters of VC may lead cells that derive from pericytes, VSMCs, monocytes or stromal cells to acquire an osteogenic phenotype. OPCs are thought to induce both intimal and medial calcification, thus promoting arterial stiffness, hypertension and cardiovascular disease. Several treatments for osteoporosis, such as biphosphonates or the anti-RANKL ligand as well as antihypertensive medication, may influence OPC number and VC.

\section{Disclosure Statement}

The authors declare no conflict of interest.

\section{References}

1 Friedenstein AJ, Chailakhyan RK, Gerasimov UV: Bone marrow osteogenic stem cells: in vitro cultivation and transplantation in diffusion chambers. Cell Tissue Kinet 1987;20: 263-272.

-2 Shirley D, Marsh D, Jordan G, McQuaid S, Li G: Systemic recruitment of osteoblastic cells in fracture healing. J Orthop Res 2005;23: 1013-1021.

3 Fadini GP, Rattazzi M, Matsumoto T, Asahara T, Khosla S: Emerging role of circulating calcifying cells in the bone-vascular axis. Circulation 2012;125:2772-2781.

4 Bianco P, Sacchetti B, Riminucci M: Osteoprogenitors and the hematopoietic microenvironment. Best Pract Res Clin Haematol 2011;24:37-47.

5 Pikilidou MI, Yavropoulou MP, Scuteri A: Can antihypertensive medication interfere with the vicious cycle between hypertension and vascular calcification? Cardiovasc Drugs Ther 2014;28:61-71.
6 Lian JB, Stein GS: Runx2/Cbfa1: a multifunctional regulator of bone formation. Curr Pharm Des 2003;9:2677-2685.

7 Shemesh J, Motro M, Morag-Koren N, Tenenbaum A, Apter S, Weiss A, Grossman E: Coronary artery calcification predicts longterm mortality in hypertensive adults. Am J Hypertens 2011;24:681-686.

-8 Drueke TB: Arterial intima and media calcification: distinct entities with different pathogenesis or all the same? Clin J Am Soc Nephrol 2008;3:1583-1584.

-9 Proudfoot D, Shanahan CM: Biology of calcification in vascular cells: intima versus media. Herz 2001;26:245-251.

10 Altunkan S, Oztas K, Seref B: Arterial stiffness index as a screening test for cardiovascular risk: a comparative study between coronary artery calcification determined by electron beam tomography and arterial stiffness index determined by a VitalVision device in asymptomatic subjects. Eur J Intern Med 2005;16:580-584.
11 Aoki A, Kojima F, Uchida K, Tanaka Y, Nitta $\mathrm{K}$ : Associations between vascular calcification, arterial stiffness and bone mineral density in chronic hemodialysis patients. Geriatr Gerontol Int 2009;9:246-252.

12 DeLoach SS, Berns JS: Arterial stiffness and vascular calcification in dialysis patients: new measures of cardiovascular risk. Semin Dial 2007;20:477-479.

13 Eghbali-Fatourechi GZ, Lamsam J, Fraser D, Nagel D, Riggs BL, Khosla S: Circulating osteoblast-lineage cells in humans. N Engl J Med 2005;352:1959-1966.

14 Fadini GP, Albiero M, Menegazzo L, Boscaro E, Vigili de KS, Agostini C, Cabrelle A, Binotto G, Rattazzi M, Bertacco E, Bertorelle R, Biasini L, Mion M, Plebani M, Ceolotto G, Angelini A, Castellani C, Menegolo M, Grego F, Dimmeler S, Seeger F, Zeiher A, Tiengo A, Avogaro A: Widespread increase in myeloid calcifying cells contributes to ectopic vascular calcification in type 2 diabetes. Circ Res 2011;108:1112-1121. 
15 Hegyi L, Gannon FH, Glaser DL, Shore EM, Kaplan FS, Shanahan CM: Stromal cells of fibrodysplasia ossificans progressiva lesions express smooth muscle lineage markers and the osteogenic transcription factor Runx $2 / \mathrm{Cbfa}-$ 1 : clues to a vascular origin of heterotopic ossification? J Pathol 2003;201:141-148.

16 Collett GD, Canfield AE: Angiogenesis and pericytes in the initiation of ectopic calcification. Circ Res 2005;96:930-938.

17 Jakoby MG, Semenkovich CF: The role of osteoprogenitors in vascular calcification. Curr Opin Nephrol Hypertens 2000;9:11-15.

-18 Bostrom K, Watson KE, Stanford WP, Demer LL: Atherosclerotic calcification: relation to developmental osteogenesis. Am J Cardiol 1995;75:88B-91B.

19 Dao HH, Essalihi R, Bouvet C, Moreau P: Evolution and modulation of age-related medial elastocalcinosis: impact on large artery stiffness and isolated systolic hypertension. Cardiovasc Res 2005;66:307-317.

20 Madhu V, Li CJ, Dighe AS, Balian G, Cui Q: 33 BMP-non-responsive Sca1+ CD73+ CD44+ mouse bone marrow derived osteoprogenitor cells respond to combination of VEGF and BMP-6 to display enhanced osteoblastic differentiation and ectopic bone formation. PLoS One 2014;9:e103060.

21 Al-Aly Z: Medial vascular calcification in diabetes mellitus and chronic kidney disease: the role of inflammation. Cardiovasc Hematol Disord Drug Targets 2007;7:1-6.

$\checkmark 22$ Csiszar A, Smith KE, Koller A, Kaley G, Edwards JG, Ungvari Z: Regulation of bone morphogenetic protein-2 expression in endothelial cells: role of nuclear factor-kappaB activation by tumor necrosis factor-alpha, $\mathrm{H} 2 \mathrm{O} 2$, and high intravascular pressure. Circulation 2005; 111:2364-2372.

-23 Yao Y, Bennett BJ, Wang X, Rosenfeld ME, Giachelli C, Lusis AJ, Bostrom KI: Inhibition of bone morphogenetic proteins protects against atherosclerosis and vascular calcification. Circ Res 2010;107:485-494.

24 Yao Y, Jumabay M, Ly A, Radparvar M, Cubberly MR, Bostrom KI: A role for the endothelium in vascular calcification. Circ Res 2013; 113:495-504.

-25 Speer MY, Yang HY, Brabb T, Leaf E, Look A, Lin WL, Frutkin A, Dichek D, Giachelli CM: Smooth muscle cells give rise to osteochondrogenic precursors and chondrocytes in calcifying arteries. Circ Res 2009;104:733-741.

-26 Doehring LC, Heeger C, Aherrahrou Z, Kaczmarek PM, Erdmann J, Schunkert H, Ehlers EM: Myeloid CD34+CD13+ precursor cells transdifferentiate into chondrocyte-like cells in atherosclerotic intimal calcification. Am J Pathol 2010;177:473-480.

27 Khosla S: The bone and beyond: a shift in calcium. Nat Med 2011;17:430-431.

-28 Giallauria F, Ling SM, Schreiber C, Maggio M, Shetty V, Muller D, Vigorito C, Ferrucci L, Najjar SS: Arterial stiffness and bone demineralization: the Baltimore longitudinal study of aging. Am J Hypertens 2011;24:970-975.
9 Frost ML, Grella R, Millasseau SC, Jiang BY, Hampson G, Fogelman I, Chowienczyk PJ: Relationship of calcification of atherosclerotic plaque and arterial stiffness to bone mineral density and osteoprotegerin in postmenopausal women referred for osteoporosis screening. Calcif Tissue Int 2008;83:112-120.

30 Mikumo M, Okano H, Yoshikata R, Ishitani K, Ohta $\mathrm{H}$ : Association between lumbar bone mineral density and vascular stiffness as assessed by pulse wave velocity in postmenopausal women. J Bone Miner Metab 2009;27:89-94.

31 Seo SK, Cho S, Kim HY, Choi YS, Park KH, Cho DJ, Lee BS: Bone mineral density, arterial stiffness, and coronary atherosclerosis in healthy postmenopausal women. Menopause 2009;16:937-943.

32 Sumino H, Ichikawa S, Kasama S, Takahashi T, Kumakura H, Takayama Y, Kanda T, Sakamaki T, Kurabayashi M: Elevated arterial stiffness in postmenopausal women with osteoporosis. Maturitas 2006;55:212-218.

3 Hirose $\mathrm{K}$, Tomiyama H, Okazaki R, Arai T, Koji Y, Zaydun G, Hori S, Yamashina A: Increased pulse wave velocity associated with reduced calcaneal quantitative osteo-sono index: possible relationship between atherosclerosis and osteopenia. J Clin Endocrinol Metab 2003;88:2573-2578.

34 Zaydun G, Tomiyama H, Hashimoto H, Arai T, Koji Y, Yambe M, Motobe K, Hori S, Yamashina A: Menopause is an independent factor augmenting the age-related increase in arterial stiffness in the early postmenopausal phase. Atherosclerosis 2006; 184:137-142.

- 35 Tanaka K, Inaba M, Goto H, Nagata-Sakurai M, Sakai S, Yamada S, Ueda M, Ishimura E, Nishizawa Y: Paraarticular trabecular bone loss at the ultradistal radius and increased arterial stiffening in postmenopausal patients with rheumatoid arthritis. J Rheumatol 2006; 33:652-658.

36 Blumenthal HT, Lansing AI, Wheeler PA: Calcification of the media of the human aorta and its relation to intimal arteriosclerosis, ageing and disease. Am J Pathol 1944;20:665-687.

37 Kim BJ, Choi SY, Lee SH, Kim CK, Ryu WS, Han MK, Oh BH, Bae HJ, Yoon BW: Advanced coronary artery calcification is associated with ischemic stroke. Cerebrovasc Dis 2010;30:93-100.

38 Luo G, Ducy P, McKee MD, Pinero GJ, Loyer E, Behringer RR, Karsenty G: Spontaneous calcification of arteries and cartilage in mice lacking matrix Gla protein. Nature 1997;386: 78-81.

39 Pateinakis P, Papagianni A, Douma S, Efstratiadis G, Memmos D: Associations of fetuinA and osteoprotegerin with arterial stiffness and early atherosclerosis in chronic hemodialysis patients. BMC Nephrol 2013;14:122.

40 Guerin AP, London GM, Marchais SJ, Metivier F: Arterial stiffening and vascular calcifications in end-stage renal disease. Nephrol Dial Transplant 2000;15:1014-1021.

41 Temmar M, Liabeuf S, Renard C, Czernichow S, Esper NE, Shahapuni I, Presne C, Makdas- si R, Andrejak M, Tribouilloy C, Galan P, Safar ME, Choukroun G, Massy Z: Pulse wave velocity and vascular calcification at different stages of chronic kidney disease. J Hypertens 2010;28:163-169.

-42 Toussaint ND, Kerr PG: Vascular calcification and arterial stiffness in chronic kidney disease: implications and management. $\mathrm{Ne}$ phrology (Carlton) 2007;12:500-509.

43 Niederhoffer N, Lartaud-Idjouadiene I, Giummelly P, Duvivier C, Peslin R, Atkinson J: Calcification of medial elastic fibers and aortic elasticity. Hypertension 1997;29:999-1006.

44 Essalihi R, Dao HH, Yamaguchi N, Moreau P: A new model of isolated systolic hypertension induced by chronic warfarin and vitamin $\mathrm{K} 1$ treatment. Am J Hypertens 2003;16:103-110.

45 McEniery CM, McDonnell BJ, So A, Aitken S, Bolton CE, Munnery M, Hickson SS, Yasmin, Maki-Petaja KM, Cockcroft JR, Dixon AK, Wilkinson IB: Aortic calcification is associated with aortic stiffness and isolated systolic hypertension in healthy individuals. Hypertension 2009;53:524-531.

46 Cecelja M, Jiang B, Bevan L, Frost ML, Spector TD, Chowienczyk PJ: Arterial stiffening relates to arterial calcification but not to noncalcified atheroma in women. A twin study. J Am Coll Cardiol 2011;57:1480-1486.

47 Blaha MJ, Budoff MJ, Rivera JJ, Katz R, O'Leary DH, Polak JF, Takasu J, Blumenthal RS, Nasir K: Relationship of carotid distensibility and thoracic aorta calcification: multiethnic study of atherosclerosis. Hypertension 2009;54:1408-1415.

48 Gauthier-Bastien A, Ung RV, Lariviere R, Mac-Way F, Lebel M, Agharazii M: Vascular remodeling and media calcification increases arterial stiffness in chronic kidney disease. Clin Exp Hypertens 2014;36:173-180.

49 AlGhatrif M, Strait JB, Morrell CH, Canepa M, Wright J, Elango P, Scuteri A, Najjar SS, Ferrucci L, Lakatta EG: Longitudinal trajectories of arterial stiffness and the role of blood pressure: the Baltimore Longitudinal Study of Aging. Hypertension 2013;62:934-941.

50 Scuteri A, Morrell CH, Orru M, Strait JB, Tarasov KV, Ferreli LA, Loi F, Pilia MG, Delitala A, Spurgeon H, Najjar SS, AlGhatrif M, Lakatta EG: Longitudinal perspective on the conundrum of central arterial stiffness, blood pressure, and aging. Hypertension 2014;64: 1219-1227.

51 Pirro M, Schillaci G, Mannarino MR, Scarponi AM, Manfredelli MR, Callarelli L, Leli C, Fabbriciani G, Helou RS, Bagaglia F, Mannarino E: Circulating immature osteoprogenitor cells and arterial stiffening in postmenopausal osteoporosis. Nutr Metab Cardiovasc Dis 2011;21:636-642.

52 Pirro M, Manfredelli MR, Schillaci G, Helou RS, Bagaglia F, Melis F, Scalera GB, Scarponi AM, Gentile E, Mannarino E: Association between circulating osteoblast progenitor cells and aortic calcifications in women with postmenopausal osteoporosis. Nutr Metab Cardiovasc Dis 2013;23:466-472. 
53 Mangiafico RA, Alagona C, Pennisi P, Parisi N, Mangiafico M, Purrello F, Fiore CE: Increased augmentation index and central aortic blood pressure in osteoporotic postmenopausal women. Osteoporos Int 2008;19:4956.

54 Pal SN, Rush C, Parr A, Van CA, Golledge J: Osteocalcin positive mononuclear cells are associated with the severity of aortic calcification. Atherosclerosis 2010;210:88-93.

55 Gossl M, Modder UI, Atkinson EJ, Lerman A, Khosla S: Osteocalcin expression by circulating endothelial progenitor cells in patients with coronary atherosclerosis. J Am Coll Cardiol 2008;52:1314-1325.

-56 Ungvari Z, Csiszar A, Kaminski PM, Wolin MS, Koller A: Chronic high pressure-induced arterial oxidative stress: involvement of protein kinase C-dependent $\mathrm{NAD}(\mathrm{P}) \mathrm{H}$ oxidase and local renin-angiotensin system. Am J Pathol 2004;165:219-226.

-57 Pirro M, Leli C, Fabbriciani G, Manfredelli MR, Callarelli L, Bagaglia F, Scarponi AM, Mannarino E: Association between circulating osteoprogenitor cell numbers and bone mineral density in postmenopausal osteoporosis. Osteoporos Int 2010;21:297-306.

58 Peris P, Atkinson EJ, Gossl M, Kane TL, McCready LK, Lerman A, Khosla S, McGregor
UI: Effects of bisphosphonate treatment on circulating osteogenic endothelial progenitor cells in postmenopausal women. Mayo Clin Proc 2013;88:46-55.

59 Helas S, Goettsch C, Schoppet M, Zeitz U, Hempel U, Morawietz H, Kostenuik PJ, Erben RG, Hofbauer LC: Inhibition of receptor activator of NF- $\mathrm{kB}$ ligand by denosumab attenuates vascular calcium deposition in mice. Am J Pathol 2009;175:473-478.

60 Samelson EJ, Miller PD, Christiansen C, Daizadeh NS, Grazette L, Anthony MS, Egbuna O, Wang A, Siddhanti SR, Cheung AM, Franchimont N, Kiel DP: RANKL inhibition with denosumab does not influence 3-year progression of aortic calcification or incidence of adverse cardiovascular events in postmenopausal women with osteoporosis and high cardiovascular risk. J Bone Miner Res 2014;29:450-457.

-61 Hampson G, Edwards S, Conroy S, Blake GM, Fogelman I, Frost ML: The relationship between inhibitors of the Wnt signalling pathway (Dickkopf-1(DKK1) and sclerostin), bone mineral density, vascular calcification and arterial stiffness in post-menopausal women. Bone 2013;56:42-47.

62 Brandenburg VM, Kramann R, Koos R, Kruger T, Schurgers L, Muhlenbruch G, Hubner S,
Gladziwa U, Drechsler C, Ketteler M: Relationship between sclerostin and cardiovascular calcification in hemodialysis patients: a cross-sectional study. BMC Nephrol 2013;14:219.

63 Viaene L, Behets GJ, Claes K, Meijers B, Blocki F, Brandenburg V, Evenepoel P, D'Haese PC: Sclerostin: another bone-related protein related to all-cause mortality in haemodialysis? Nephrol Dial Transplant 2013; 28:3024-3030.

64 Lee DO, Kim H, Ku SY, Kim SH, Kim JG: Association between polymorphisms in sclerostin, Dickkopfs and secreted frizzled-related protein genes and bone mineral density in postmenopausal Korean women. Gynecol Obstet Invest 2014;77:186-193.

65 Pikilidou MI, Yavropoulou MP, Scuteri A: Can antihypertensive medication interfere with the vicious cycle between hypertension and vascular calcification? Cardiovasc Drugs Ther 2014;28:61-71.

66 Ehara S, Kobayashi Y, Yoshiyama M, Shimada K, Shimada Y, Fukuda D, Nakamura Y, Yamashita H, Yamagishi H, Takeuchi K, Naruko T, Haze K, Becker AE, Yoshikawa J, Ueda M: Spotty calcification typifies the culprit plaque in patients with acute myocardial infarction: an intravascular ultrasound study. Circulation 2004;110:3424-3429. 